\title{
Características de Carcaça e Composição Corporal de Touros Jovens da Raça Nelore Terminados em Diferentes Sistemas
}

\author{
Marcelo Pereira Macedo², João Francisco Pereira Bastos ${ }^{3}$, Evaristo Bianchini Sobrinho ${ }^{3}$, \\ Flávio Dutra de Resende ${ }^{4}$, Leopoldo Andrade de Figueiredo ${ }^{2}$, Antônio José Rodrigues Neto ${ }^{5}$
}

\begin{abstract}
RESUMO - O objetivo do trabalho foi avaliar comparativamente as características de carcaça e a composição corporal de machos jovens da raça Nelore não-castrados, filhos de touros com diferencial positivo (Linhagem Seleção) ou nulo (Linhagem Controle) para ganho de peso aos 378 dias de idade. Utilizaram-se informações de 92 zebuínos Nelore, com peso de abate médio de $456,00 \mathrm{~kg}$, sendo 51 animais pertencentes à Linhagem Seleção e 41 animais da Linhagem Controle, foram criados em pastagens cultivadas até os 18 meses, quando foram alocados nos dois sistemas de terminação, de forma a compor grupos homogêneos quanto ao peso e filiação. Os animais de confinamento receberam, em baias individuais, ração para possibilitar ganhos de 1,0 kg/cab/dia. Antes do abate, os animais foram submetidos a jejum e pesados, quando se obteve o peso de abate. Após o armazenamento das carcaças em câmara fria, obteve-se a seção da $9^{\mathrm{a}}-10^{\mathrm{a}}-11^{\mathrm{a}}$ costelas. Não houve efeito significativo de linhagem para nenhuma das características analisadas, exceto para a porcentagem de ossos, sendo que os animais da Linhagem Seleção superaram os animais da Linhagem Controle. O regime de terminação apresentou efeito significativo para a quase totalidade das características estudadas, com exceção para as características de composição corporal. Não houve efeito significativo de interação entre linhagem e terminação. As classes de idade apresentaram efeito significativo para as características peso de abate, peso de carcaça quente, peso da gordura renal-pélvica-ingüinal, porcentagem de músculo, gordura e osso.
\end{abstract}

Palavras-chave: bovino de corte, produção de carne, qualidade da carne, seleção, zebuínos

\section{Carcass Traits and Body Composition of Young Nellore Bulls Finished at Different Feeding Regime}

\begin{abstract}
The objective of this work was to evaluate comparatively the carcass traits and body composition of young Nellore breed intact male, sons of bulls with differentials positive (Selection Lineage) or null (Control Lineage) at weight gain at 378 days of age. Data from 92 Nellore cattle, with $456.00 \mathrm{~kg}$ of slaughter weight, being 51 animals of Selection Lineage and 41 animals of Control Lineage. They were raised in cultivated pastures until 18 months of age, when were designated in two finishing systems, to arrange homogeneous groups to weight and filiation. The animals were fed, in individual pens, with ration for gains of $1.0 \mathrm{~kg} / \mathrm{day}$. Before slaughter, the animals were fasted and weighed, when the slaughter weight was obtained. After carcass storage in cold chamber, the section of $9^{\text {th }}-10^{\text {th }}-11^{\text {th }}$ ribs was obtained. There were no significant effects of lineage were for neither traits studied, except for the bone percentage, and the animals of Selection Lineage were superior than the animals of Control Lineage. The finishing system showed significant effects for all traits studied, except for the body composition. There were no significant effects of interaction between lineage and finishing system. The classes of age showed significant effects for the traits slaughter weight, hot carcass weight, kidney fat weight, muscle, fat and bone percentage.
\end{abstract}

Key Words: beef cattle, meat production, meat quality, selection, zebu cattle

\section{Introdução}

A pecuária de corte no Brasil encontra-se em fase de expansão e de modernização dos sistemas de produção, face aos inexoráveis desafios impostos ao país pelo processo de globalização da economia. Tais mudanças conjunturais forçaram uma alteração na mentalidade dos pecuaristas, que, pressionados pelas mudanças econômicas, estão se transformando de tradicionais criadores de bois em modernos produtores de carne bovina de qualidade.

Apesar de alguns inconvenientes de manejo, desde o final da década de 1980, tem aumentado consideravelmente o uso de animais não-castrados na

\footnotetext{
1 Parte da dissertação do primeiro autor apresentada à Faculdade de Engenharia de llha Solteira/UNESP, para obtenção do título de Mestre em Zootecnia.

2 Pesquisador Científico do Instituto de Zootecnia - Centro de Nutrição e Alimentação Animal - APTA/SAA/SP. Rua Heitor Penteado, 56, Centro, Nova Odessa, SP. Caixa Postal 60, CEP: 13460-000. E.mail: macedo@izsp.br

3 Professor da Faculdade de Engenharia/UNESP. Campus de llha Solteira, SP.

4 Pesquisador Científico do Instituto de Zootecnia - Agência Paulista de Tecnologia de Agronegócios - APTA/SAA-SP. E.mail: eezcol@colina.com.br; figueiredo@izsp.br

${ }^{5}$ Engenheiro-Agrônomo - Escritório de Desenvolvimento Rural de Andradina/CATI/SAA/SP.
} 
produção de carne e existem pesquisas concluindo que animais não-castrados apresentam maior ganho de peso, melhor eficiência alimentar e, conseqüentemente, menor consumo de alimentos, menor quantidade gordura renal e pélvica, maior área do olho de lombo e maior quantidade da porção comestível (CHAMPAGNE et al., 1969; FIELD, 1971; JACOBS et al., 1977).

Nesse contexto, a seleção dos reprodutores assume grande importância. Alguns trabalhos demonstram a eficácia da seleção direta ou indireta sobre características de crescimento de bovinos de corte (AARON et al., 1986; MACNEIL et al., 1992). Segundo RAZOOK et al. (1994), uma das grandes vantagens da seleção direta seria melhorar o valor genético médio do rebanho, ou seja, espera-se que, em rebanhos submetidos à seleção, os indivíduos acima da média no caráter selecionado tenham valor genético diferenciado.

O uso de reprodutores testados é um dos fatores fundamentais para o sucesso da pecuária de corte e embora o número de touros avaliados esteja muito aquém das necessidades do país, são poucos os trabalhos sobre a utilização de reprodutores Nelore em acasalamentos com fêmeas comerciais.

De acordo com ALLEONI (1995), para a maximização da porção comestível da carcaça bovina, é necessário estimar a composição corporal dos animais, especificamente a composição da carcaça, visando adequar o animal para o seu melhor peso de abate, evitando a deposição excessiva de gordura, elevando dessa forma o rendimento de carne aproveitável.

LEME (1993) e ALLEONI (1995) consideram que a relativa escassez de trabalhos estudando a composição corporal de zebuínos no Brasil, particularmente da raça Nelore, tem dificultado o estabelecimento das exigências nutricionais para as diversas categorias dessa espécie. A composição da carcaça deve ser avaliada com o propósito de determinar com maior precisão as diferenças que, eventualmente, possam existir devido a fatores genotípicos ou ambientes.

Assim, o objetivo deste trabalho foi comparar as características de carcaça e a composição corporal de machos jovens da raça Nelore, não-castrados, filhos de touros com diferencial positivo ou nulo, terminados em confinamento e a pasto.

\section{Material e Métodos}

O experimento foi conduzido na Estação Experimental de Zootecnia de Andradina (EEZ de
Andradina), onde foram utilizados 92 zebuínos da raça Nelore (Bos indicus), não-castrados, nascidos em duas estações de monta consecutivas nos anos de 1993 e 1994. Esses animais constituíram a progênie de touros Nelore com diferenciais de seleção positivo e nulo para ganho de peso aos 378 dias de idade, denominados, respectivamente, de Linhagem Seleção (LS) e Linhagem Controle (LC), oriundos do Programa de Melhoramento Genético da Raça Nelore do Instituto de Zootecnia.

Os bovinos foram obtidos através do acasalamento de touros Nelore PO com vacas comerciais da mesma raça. Os animais foram criados e recriados em pastagens cultivadas, compostas de capim colonião (Panicum maximum Jacq.) e braquiária decumbens (Brachiaria decumbens Stapf.) do nascimento até a idade média de 18 meses, sendo suplementados apenas com mistura mineral. Nesta ocasião, foram pesados e distribuídos aleatoriamente em dois regimes de terminação, em confinamento e a pasto, de forma a compor grupos homogêneos quanto ao peso e filiação (Linhagens).

Os animais destinados ao confinamento foram alojados em baias individuais com dez metros quadrados de área, dotadas de comedouros cobertos e bebedouros individuais, piso concretado e solário. Os animais foram arraçoados uma vez ao dia, pela manhã às 9 horas. A alimentação consistia de $60 \%$ de volumoso (silagem de milho e de sorgo) e $40 \%$ de concentrado, confeccionado com milho triturado, farelo de algodão e minerais. As dietas foram balanceadas de acordo com as normas para gado de corte do NATIONAL RESEARCH COUNCIL - NRC (1984), visando ganhos de 1,0 kg/cab/dia.

Os animais destinados à terminação a pasto foram mantidos em pastagens de capim-colonião e braquiária decumbens e suplementados com mistura mineral balanceada.

Ainda na fazenda, antes do abate, os animais foram submetidos a jejum alimentar e hídrico de 16 horas e pesados, para obtenção do peso de abate (PABATE), e embarcados para o abatedouro.

Os animais foram abatidos pelo sistema convencional de abate no Frigorífico Angelelli Ltda, Piracicaba, $\mathrm{SP}$, seguindo-se o fluxo operacional próprio do frigorífico, em 04/01/96 e 11/01/1997 para os animais terminados em confinamento e em 08/05/1996 e 17/06/1997 para os animais terminados a pasto.

No frigorífico, os animais foram submetidos a um período de nove horas de jejum, somente com acesso à água nos currais de espera. A concussão cerebral foi 
seguida pela sangria feita através da seção da artéria jugular. Após a separação da cabeça, a retirada do couro e completada a evisceração, as carcaças foram divididas com uma serra elétrica obtendo-se duas meias-carcaças. A gordura renal-pélvica-ingüinal (GRPI) foi pesada individualmente antes do resfriamento. Em seguida, as duas meias-carcaças foram pesadas, lavadas e armazenadas em câmara fria por um período de aproximadamente 18 horas, à temperatura de $4^{\circ} \mathrm{C}$.

Utilizando-se as meias-carcaças esquerdas resfriadas, foram retirados os cortes transversais da $9^{\mathrm{a}}$ $10^{\mathrm{a}}-11^{\mathrm{a}}$ costelas, incluindo as porções das vértebras torácicas, que se articulam dorsalmente com as costelas, que segundo HANKINS e HOWE (1946), correspondente à seção HH. Estas seções foram pesadas e em seguida dissecadas e separadas em músculo, gordura e ossos, sendo estes componentes pesados e calculada a porcentagem de cada um nas $9^{\mathrm{a}}-10^{\mathrm{a}}-11^{\mathrm{a}}$ costelas (seção $\mathrm{HH}$ ).

De acordo com a metodologia descrita por MÜLLER (1980), foram obtidas as medidas da área do olho de lombo (AOL) e a espessura de gordura subcutânea (EGS), ambas tomadas à altura da $12^{\mathrm{a}}$ costela, usando a seção transversal do músculo Longissimus dorsi.

As análises das amostras de carne foram efetuadas no Laboratório de Carcaças do Centro de Nutrição e Alimentação Animal do Instituto de Zootecnia de São Paulo, em Nova Odessa, SP, para obtenção da composição corporal e força de cisalhamento (maciez). O método adotado para a determinação da maciez foi o de KASTNER e HENDRICKS (1969).

As variáveis submetidas à análise de variância, por intermédio do método dos quadrados mínimos pelo procedimento General Linear Model (SAS, 1997), foram: PABATE, peso de carcaça quente (PCQ), rendimento de carcaça quente (RCQ), peso da gordura renal-pélvicaingüinal(GRPI), área do olho de lombo(AOL), espessura de gordura subcutânea (EGS), força de cisalhamento (FC), porcentagem de músculo (\% MUSC), porcentagem de gordura ( $\%$ GORD) e porcentagem de osso $(\%$ OSS). Preliminarmente, foram efetuadas análises de variância onde não se registraram efeitos significativos da idade sobrenenhuma das características estudadas. Assim, os animais foram classificados em seis classes de idade e estas incluídas como covariáveis em novas análises estatísticas. $\mathrm{O}$ modelo estatístico usado foi o seguinte:

$$
\mathrm{Y}_{\mathrm{ijkl}}=\mu+\mathrm{L}_{\mathrm{i}}+\mathrm{T}_{\mathrm{j}}+(\mathrm{L} \text { x T })_{\mathrm{ij}}+\mathrm{I}_{\mathrm{k}}+\mathrm{e}_{\mathrm{ijkl}}
$$

em que: $\mathrm{Y}_{\mathrm{ijkl}}=$ a variável dependente analisada (PABATE; PCQ; RCQ; GRPI; AOL; EG; FC; \% MUSC; \% GORD e $\%$ OSS), $\mu=$ a média geral; L é o efeito fixo da i-ésima linhagem $(1,2) ; \mathrm{T}=\mathrm{o}$ efeito fixo da j-ésima terminação $(1,2) ;(\mathrm{L} x \mathrm{~T})_{\mathrm{ij}}=\mathrm{o}_{\mathrm{o}}$ efeito da interação entre linhagem ${ }_{\mathrm{i}} \mathrm{e}$ terminação $\mathrm{j}$ I é o efeito fixo da k-ésima classe de idade

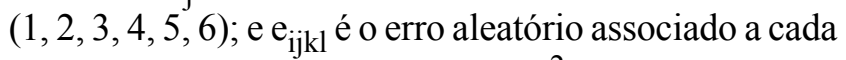
observação com distribuição $\mathrm{N}\left(\mu, \sigma^{2}\right)$.

\section{Resultados e Discussão}

As Tabelas 1, 2 e 3 sumarizam os resultados da análise de variância do presente estudo. Não houve efeito significativo $(\mathrm{P}>0,05)$ de linhagem para nenhuma das características analisadas, exceto para a porcentagem de ossos ( $\%$ OSS), sendo que os animais da Linhagem Seleção superaram $(\mathrm{P}<0,05)$ os animais da

Tabela 1 - Resumo da análise de variância para peso de abate (PABATE), peso de carcaça quente (PCQ) e rendimento de carcaça quente (RCQ)

Table 1 - Summary of analysis of variance for slaughter weight (PABATE), hot carcass weight (PCQ) and hot dressing percentage (RCQ)

\begin{tabular}{|c|c|c|c|c|c|c|c|}
\hline \multirow{2}{*}{$\begin{array}{l}\text { Fonte de variação } \\
\text { Source of variation }\end{array}$} & \multirow{2}{*}{$\begin{array}{c}\mathrm{df}^{1} \\
g l\end{array}$} & \multicolumn{2}{|c|}{ PABATE } & \multicolumn{2}{|c|}{ PCQ } & \multicolumn{2}{|c|}{ RCQ } \\
\hline & & $\begin{array}{c}\mathrm{QM}^{2} \\
M S\end{array}$ & $\mathrm{~F}$ & $\begin{array}{l}\text { QM } \\
M S\end{array}$ & $\mathrm{~F}$ & $\begin{array}{l}\text { QM } \\
M S\end{array}$ & $\mathrm{~F}$ \\
\hline $\begin{array}{l}\text { Linhagem }(\mathrm{L}) \\
\text { Lineage }\end{array}$ & 1 & 5088,72 & 3,78 & 910,50 & 1,63 & 5,64 & 2,56 \\
\hline $\begin{array}{l}\text { Terminação }(\mathrm{T}) \\
\text { Finishing }\end{array}$ & 1 & 36004,38 & $26,73^{*}$ & 5125,04 & $9,20^{*}$ & 73,48 & $33,35^{*}$ \\
\hline $\begin{array}{l}\mathrm{LxT} \\
\text { Classes de idade }\end{array}$ & $\begin{array}{l}1 \\
5\end{array}$ & $\begin{array}{l}1210,63 \\
4449,51\end{array}$ & $\begin{array}{l}0,90 \\
3,30 *\end{array}$ & $\begin{array}{r}245,79 \\
2064,70\end{array}$ & $\begin{array}{l}0,44 \\
3,71^{*}\end{array}$ & $\begin{array}{l}0,37 \\
3,24\end{array}$ & $\begin{array}{l}0,17 \\
1,47\end{array}$ \\
\hline $\begin{array}{l}\text { Classes of age } \\
\text { Erro } \\
\text { Error }\end{array}$ & 83 & 1347,01 & - & 557,06 & - & 2,20 & - \\
\hline
\end{tabular}

* Significativo $(P<0,05)$ (significant at $[P<0.5])$.

1 graus de liberdade (Degrees of freedom).

2 Quadrado médio (Mean square). 
Linhagem Controle. Biologicamente, esse resultado pode ser explicado em função de que os músculos se prendem às extremidades dos ossos e, portanto, animais com maior desenvolvimento muscular necessitam de um correspondente arcabouço ósseo que permita o desenvolvimento de grandes massas musculares.

Em contra-partida, o sistema de terminação afetou significativamente $(\mathrm{P}<0,05)$ a quase totalidade das características estudadas, com exceção das características de composição da seção $\mathrm{HH}$ (porcentagens de músculo, gordura e osso).

As análises de variância para PABATE, PCQ, RCQ, GRPI, AOL, EGS, FC, \% MUSC, \% GORD e \% OSS mostraram não haver efeito significativo de interação $(\mathrm{P}>0,05)$ entre linhagem e sistema de terminação, sendo, portanto, os dois efeitos estudados separadamente nas comparações de médias.

As classes de idade apresentaram efeito significativo $(\mathrm{P}<0,05)$ para as características PABATE, PCQ, GRPI, $\%$ MUSC, $\%$ GORD e \% OSS. Quanto às características de RCQ, AOL, EGS e FC não foram detectados efeitos significativos $(\mathrm{P}>0,05)$ das classes de idade.

$\mathrm{Na}$ Tabela 4 encontram-se as médias e respectivos desvios-padão das características: PABATE, PCQ, RCQ e GRPI, conforme a Linhagem dos animais. Os animais pertencentes à Linhagem Seleção apresentaram peso de abate $(462,57 \mathrm{~kg})$ significativamente superior $(\mathrm{P}<0,05)$ aos apresentados pelos animais da Linhagem Controle $(442,07 \mathrm{~kg})$, superando estes em mais de uma arroba $(20,50 \mathrm{~kg})$. Em números absolutos

Tabela 2 - Resumo da análise de variância para gordura renal-pélvica-inguinal (GRPI), área do olho de lombo (AOL), espessura de gordura subcutânea (EGS) e força de cisalhamento (FC)

Table 2 - Summary of analysis of variance for kidney fat weight (GRPI), loin eye area (AOL), fat thickness (EGS) and shear force (FC)

\begin{tabular}{|c|c|c|c|c|c|c|c|c|c|}
\hline \multirow[t]{2}{*}{$\begin{array}{l}\text { Fonte de variação } \\
\text { Source of variation }\end{array}$} & \multirow[t]{2}{*}{$\begin{array}{l}\mathrm{g} 1^{1} \\
d f\end{array}$} & \multicolumn{2}{|c|}{$\begin{array}{l}\text { GRPI } \\
Q M^{2}\end{array}$} & \multicolumn{2}{|c|}{$\mathrm{AOL}$} & \multicolumn{2}{|c|}{ EGS } & \multicolumn{2}{|c|}{$\mathrm{FC}$} \\
\hline & & $\begin{array}{l}\text { MS } \\
Q M\end{array}$ & $\begin{array}{l}\mathrm{F} \\
F\end{array}$ & $\begin{array}{l}\text { MS } \\
Q M\end{array}$ & $\begin{array}{l}\mathrm{F} \\
F\end{array}$ & $\begin{array}{l}\text { MS } \\
Q M\end{array}$ & $\begin{array}{l}\mathrm{F} \\
F\end{array}$ & $\begin{array}{l}\mathrm{MS} \\
Q M\end{array}$ & $\begin{array}{l}\mathrm{F} \\
F\end{array}$ \\
\hline $\begin{array}{l}\text { Linhagem }(\mathrm{L}) \\
\text { Lineage }\end{array}$ & 1 & 3,62 & 1,11 & 48,35 & 0,70 & 2,86 & 1,46 & 0,18 & 0,21 \\
\hline $\begin{array}{l}\text { Terminação }(\mathrm{T}) \\
\text { Finishing }\end{array}$ & 1 & 88,77 & $27,07^{*}$ & 544,10 & $7,84^{*}$ & 9,47 & $4,84^{*}$ & 9,67 & $11,38^{*}$ \\
\hline $\begin{array}{l}\mathrm{LxT} \\
\text { Classes de idade }\end{array}$ & $\begin{array}{l}1 \\
5\end{array}$ & $\begin{array}{r}0,55 \\
10,06\end{array}$ & $\begin{array}{l}0,17 \\
3,07^{*}\end{array}$ & $\begin{array}{r}38,39 \\
117,00\end{array}$ & $\begin{array}{l}0,55 \\
1,69\end{array}$ & $\begin{array}{l}0,15 \\
4,42\end{array}$ & $\begin{array}{l}0,08 \\
2,26\end{array}$ & $\begin{array}{l}1,06 \\
1,95\end{array}$ & $\begin{array}{l}1,25 \\
2,29\end{array}$ \\
\hline $\begin{array}{l}\text { Classes of age } \\
\text { Erro } \\
\text { Error }\end{array}$ & 83 & 3,28 & - & 69,41 & - & 1,95 & - & 0,85 & - \\
\hline
\end{tabular}

* Significativo $(\mathrm{P}<0,05)$ (Significant at $[P<0.5])$.

1 graus de liberdade (Degrees of freedom).

2 Quadrado médio (Mean square).

Tabela 3 - Resumo da análise de variância para a porcentagem de músculo (\% Músculo), gordura (\% Gordura) e osso (\% Osso) Table 3 - Summary of analysis of variance for muscle percentage (Muscle \%), fat percentage (Fat \%) and bone percentage (Bone \%)

\begin{tabular}{|c|c|c|c|c|c|c|c|}
\hline \multirow[t]{2}{*}{$\begin{array}{l}\text { Fonte de variação } \\
\text { Source of variation }\end{array}$} & \multirow[t]{2}{*}{$\begin{array}{c}\mathrm{df}^{1} \\
g l\end{array}$} & \multicolumn{2}{|c|}{$\begin{array}{c}\% \text { Músculo } \\
\text { Muscle } \% \\
\end{array}$} & \multicolumn{2}{|c|}{$\begin{array}{c}\% \text { Gordura } \\
\text { Fat } \%\end{array}$} & \multicolumn{2}{|c|}{$\begin{array}{l}\% \text { Osso } \\
\text { Bone } \%\end{array}$} \\
\hline & & $\begin{array}{c}\mathrm{QM}^{2} \\
M S \\
\end{array}$ & $\mathrm{~F}$ & $\begin{array}{l}\text { QM } \\
M S \\
\end{array}$ & $\mathrm{~F}$ & $\begin{array}{l}\text { QM } \\
M S \\
\end{array}$ & $\mathrm{~F}$ \\
\hline $\begin{array}{l}\text { Linhagem }(\mathrm{L}) \\
\text { Lineage }\end{array}$ & 1 & 16,25 & 1,05 & 75,27 & 3,87 & 21,75 & $6,87^{*}$ \\
\hline $\begin{array}{l}\text { Terminação }(\mathrm{T}) \\
\text { Finishing }\end{array}$ & 1 & 26,10 & 1,68 & 27,29 & 1,40 & 0,02 & 0,01 \\
\hline $\begin{array}{l}\mathrm{LxT} \\
\text { Classes de idade }\end{array}$ & $\begin{array}{l}1 \\
5\end{array}$ & $\begin{array}{r}2,17 \\
42,43\end{array}$ & $\begin{array}{l}0,14 \\
2,74^{*}\end{array}$ & $\begin{array}{r}11,26 \\
103,13\end{array}$ & $\begin{array}{l}0,58 \\
5,31^{*}\end{array}$ & $\begin{array}{r}3,37 \\
20,07\end{array}$ & $\begin{array}{l}1,07 \\
6,34^{*}\end{array}$ \\
\hline $\begin{array}{l}\text { Classes of age } \\
\text { Erro }\end{array}$ & 83 & 15,50 & - & 19,44 & - & 3,16 & - \\
\hline
\end{tabular}

Error

* Significativo $(P<0,05)$ (Significant at $[P<0.5])$.

1 graus de liberdade (Degrees of freedom).

2 Quadrado médio (Mean square). 
Tabela 4 - Médias e desvios-padrão do peso de abate (PABATE), peso de carcaça quente (PCQ), rendimento de carcaça quente (RCQ) e peso da gordura renal-pélvica-inguinal (GRPI) conforme a linhagem

Table 4 - Means and standard deviation of slaughter weight (PABATE), hot carcass weight (PCQ), hot dressing percentage (RCQ) and fat kidney weight (GRPI), according to lineage

\begin{tabular}{|c|c|c|c|c|c|c|c|c|}
\hline \multirow{2}{*}{$\begin{array}{l}\text { Linhagem } \\
\text { Lineage }\end{array}$} & \multicolumn{2}{|c|}{ PABATE $(\mathrm{kg})$} & \multicolumn{2}{|c|}{ PCQ $(\mathrm{kg})$} & \multicolumn{2}{|c|}{ RCQ(\%) } & \multicolumn{2}{|c|}{ GRPI(kg) } \\
\hline & $\begin{array}{l}\text { Média } \\
\text { Mean }\end{array}$ & $\begin{array}{c}\mathrm{DP}^{1} \\
S D\end{array}$ & $\begin{array}{l}\text { Média } \\
\text { Mean }\end{array}$ & $\begin{array}{l}\text { DP } \\
S D\end{array}$ & $\begin{array}{l}\text { Média } \\
\text { Mean }\end{array}$ & $\begin{array}{l}\mathrm{DP} \\
S D\end{array}$ & $\begin{array}{l}\text { Média } \\
\text { Mean }\end{array}$ & $\begin{array}{l}\mathrm{DP} \\
S D\end{array}$ \\
\hline $\begin{array}{l}\text { Seleção } \\
\text { Selection }\end{array}$ & $462,57^{\mathrm{a}}$ & 40,47 & $265,97^{\mathrm{a}}$ & 24,93 & $57,50^{\mathrm{a}}$ & 2,06 & $5,89^{\mathrm{a}}$ & 2,09 \\
\hline $\begin{array}{l}\text { Controle } \\
\text { Control }\end{array}$ & $442,07^{\mathrm{a}}$ & 44,16 & $255,49^{\mathrm{a}}$ & 26,05 & $57,80^{\mathrm{a}}$ & 1,85 & $5,98^{\mathrm{a}}$ & 2,40 \\
\hline
\end{tabular}

${ }^{1}$ Desvio-padrão (Standard deviation).

Médias seguidas de mesma letra, na mesma coluna, não diferem pelo teste $F$ de Snedecor $(P>0,05)$.

Means followed by the same letters, in the same column, do not differ by $F$ test of Snedecor $(P>.05)$.

essa vantagem dos animais da Linhagem Seleção pode parecer uma cifra modesta, porém, este valor pode resultar em incremento expressivo refletindo positivamente nos índices de produtividade de uma propriedade dedicada à pecuária de corte. Esses resultados ratificam as conclusões de RAZOOK et al. (1994) favoráveis à utilização de touros de alto diferencial de seleção para a característica ganho de peso.

Os resultados obtidos para os PCQ no presente estudo, contrariam as informações da literatura. Não houve diferenças significativas $(\mathrm{P}>0,05)$ entre os PCQ das duas linhagens estudadas, apenas uma pequena vantagem para o PCQ dos animais da Linhagem Seleção $(265,97 \mathrm{~kg})$ em relação aos animais da Linhagem Controle $(255,49 \mathrm{~kg})$. Tampouco foram verificadas diferenças significativas $(\mathrm{P}>0,05)$ entre os animais das linhagens Seleção e Controle quanto ao RCQ. O peso referente a GRPI dos animais da Linhagem Seleção pode ser considerado semelhante ao peso da GRPI dos animais da Linhagem Controle. Esses resultados concordam com os achados de SAINZ (1996), que afirma haver influência da gordura renal-pélvica-ingüinal sobre o rendimento de carcaça.

Constam da Tabela 5 as médias e respectivos desvios-padrão das características qualitativas da carcaça de acordo com a linhagem: AOL, EGS e FC.

Não se observaram diferenças estatísticas para nenhuma das características supracitadas entre as linhagens. A área do músculo L. dorsi é considerada como reflexo do desenvolvimento muscular do animal. Embora não se detectassem efeitos significativos de linhagem sobre a AOL, os resultados obtidos podem ser considerados satisfatórios e indicativos de bom grau de musculosidade das carcaças dos animais do presente estudo.

As linhagens não apresentaram diferenças $(\mathrm{P}>0,05)$ de EGS. Esses resultados indicam que não houve diferenças marcantes de maturidade fisiológica entre os animais das duas linhagens avaliadas no presente estudo por ocasião do abate dos mesmos. LORENZONI et al. (1986) também não verificaram diferenças nas espessuras de gordura subcutânea em novilhos das raças Nelore e Holandesa e seus mestiços 1/2, 3/4 e 5/8 Holandês-zebu. Do mesmo modo, GALVÃO et al. (1991) não encontraram diferenças na espessura de gordura subcutânea, corrigida para $100 \mathrm{~kg}$ de peso de corpo vazio, entre animais da raça Nelore e seus mestiços com Marchigiana e Limousin, abatidos em estágios equivalentes de maturidade fisiológica.

A EGS obtida no presente estudo para os animais da Linhagem Seleção $(1,33 \mathrm{~mm})$ e da Linhagem Controle $(1,46 \mathrm{~mm})$ pode ser avaliada como insuficiente. Embora os animais tivessem atingido o peso de abate pré-estabelecido (450 kg de peso vivo), a posterior mensuração da EGS nas carcaças denota não terem esses animais atingido um grau de acabamento adequado. De certo modo, não havia expectativa de influência da linhagem dos animais sobre esta característica, devido ao fato desses zebuínos pertencerem à mesma raça e a existência de resultados de pesquisa divergentes na literatura. Em trabalho recente, JORGE et al. (1999), avaliando zebuínos de quatro raças (Gir, Guzerá, Tabapuã e Nelore), não observaram diferenças entre raças em relação à $\mathrm{AOL}$ e EGS. GALVÃO et al. (1991) também não observaram diferenças entre raças em relação à AOL. De modo 
Tabela 5 - Médias e desvios-padrão da área do olho de lombo (AOL), espessura de gordura subcutânea (EGS) e força de cisalhamento (FC) conforme a linhagem

Table 5 - Means and standard deviation of loin eye area (AOL), fat thickness (EGS) and shear force (FC), according to lineage

\begin{tabular}{|c|c|c|c|c|c|c|}
\hline \multirow{2}{*}{$\begin{array}{l}\text { Linhagem } \\
\text { Lineage }\end{array}$} & \multicolumn{2}{|c|}{$\operatorname{AOL}\left(\mathrm{cm}^{2}\right)$} & \multicolumn{2}{|c|}{ EGS(mm) } & \multicolumn{2}{|c|}{$\mathrm{FC}(\mathrm{kg})$} \\
\hline & $\begin{array}{l}\text { Média } \\
\text { Mean }\end{array}$ & $\begin{array}{l}\mathrm{DP}^{1} \\
S D\end{array}$ & $\begin{array}{l}\text { Média } \\
\text { Mean }\end{array}$ & $\begin{array}{l}\mathrm{DP} \\
S D\end{array}$ & $\begin{array}{l}\text { Média } \\
\text { Mean }\end{array}$ & $\begin{array}{l}\mathrm{DP} \\
S D\end{array}$ \\
\hline $\begin{array}{l}\text { Seleção } \\
\text { Selection }\end{array}$ & $64,19^{\mathrm{a}}$ & 9,22 & $1,33^{\mathrm{a}}$ & 1,59 & $4,64^{\mathrm{a}}$ & 0,89 \\
\hline $\begin{array}{l}\text { Controle } \\
\text { Control }\end{array}$ & $66,31^{\mathrm{a}}$ & 7,84 & $1,46^{\mathrm{a}}$ & 1,41 & $4,77^{\mathrm{a}}$ & 1,20 \\
\hline
\end{tabular}

${ }^{1}$ Desvio-padrão (Standard deviation).

Médias seguidas de mesma letra, na mesma coluna, não diferem entre si pelo teste $F$ de Snedecor $(P>0,05)$.

Means followed by the same letters, in the same column, do not differ by test $F$ of Snedecor $(P>.05)$.

diverso, MOLETTA e RESTLE (1996b) encontraram diferenças entre grupos genéticos para AOL e EGS.

A indústria frigorífica adota como padrão desejável uma espessura de gordura da ordem de 3 a $6 \mathrm{~mm}$ de gordura, com uma espessura mínima de $2 \mathrm{~mm}$. Como enfatizado anteriormente, o grau insuficiente de acabamento pode gerar problemas depreciando a qualidade da carne, como o escurecimento, o encurtamento pelo frio, e também pode contribuir de modo significativo na redução da sua maciez (FELÍCIO e NORMAN, 1978; SAINZ, 1996). Por outro lado, o excesso de gordura acima de sete milímetros é inútil e praticamente sem valor comercial sendo aparado a um mínimo pelos varejistas no ato da comercialização. De fato, cortes cárneos com gordura excessiva interessam apenas a nichos de mercado muito pequenos, como o mercado japonês (SAINZ, 1996).

Os dados de PCQ e de AOL obtidos no presente estudo são consistentes com o trabalho de RESTLE et al. (1994). Os autores relataram ao avaliar as características de carcaça serem as carcaças de animais inteiros superiores em peso e conformação, apresentando maior proporção de músculo. Entretanto, no nosso meio, o principal aspecto negativo das carcaças de animais inteiros é a deficiência de gordura de cobertura, a qual, além dos aspectos mencionados anteriormente, pode resultar em maior perda de água durante o processo de resfriamento das carcaças.

A carne bovina pode ser classificada como macia até um valor máximo da força de cisalhamento, medida no aparelho de Warner-Bratzler, aproximadamente igual a $4,2 \mathrm{~kg}$. A força de cisalhamento observada no presente estudo (Tabela 5) caracteriza a carne oriunda desses animais, de ambas as linhagens, como ligeiramente dura. Esses resultados são condizen- tes com diversos trabalhos de pesquisa, devido ao fato de as raças zebuínas e seus cruzamentos serem reconhecidos por produzir uma carne menos macia em comparação às raças taurinas $(\mathrm{KOCH}$ et al., 1982; WHEELER et al., 1990; SHACKELFORD et al., 1995; MOLETTA e RESTLE, 1996a; MOURA et al. 1998).

Os números relativamente elevados da FC obtidos no presente estudo podem ser atribuídos a dois fatores não-genéticos: ao estresse resultante do manejo da pesagem de abate e embarque nos caminhões boiadeiros, ainda na fazenda, a viagem e ao prolongado período de jejum a que os animais foram submetidos antes do sacrifício, somando cerca de 33 horas (16 horas + oito horas embarcados + nove horas nos currais sanitários do frigorífico). LUCHIARI FILHO et al. (1981), comparando tourinhos Nelores e meiosangue Marchigiana-Nelore e Chianina-Nelore, também não verificaram diferenças entre raças para a força de cisalhamento. No entanto, MOLETTA e RESTLE (1996a) verificaram diferenças entre grupos genéticos para a força de cisalhamento.

As proporções médias estimadas e respectivos desvios-padrão de músculo, gordura e ossos dos animais de ambas as linhagens são apresentadas na Tabela 6.

Não houve diferença significativa $(\mathrm{P}>0,05)$ para as características \% MUSC e \% GORD, mas verificou-se diferença para a característica \% OSS. Para os resultados da composição da seção $\mathrm{HH}$ esperava-se o mesmo comportamento observado quanto às características qualitativas das carcaças, isto é, não havia expectativa quanto à influência da linhagem sobre as mesmas. Contudo, os resultados revelam que os animais da raça Nelore apresentam uma composição de carcaça que atende aos anseios do mercado consumidor. 
Tabela 6 - Médias e desvios-padrão da porcentagem de músculo, gordura e osso do corte da seção $\mathrm{H}-\mathrm{H}$, conforme a linhagem

Table 6 - Means and standard deviation of muscle, fat and bone percentage of $\mathrm{HH}$ section, according to lineage

\begin{tabular}{|c|c|c|c|c|c|c|}
\hline \multirow[t]{3}{*}{$\begin{array}{l}\text { Linhagem } \\
\text { Lineage }\end{array}$} & \multicolumn{2}{|c|}{$\begin{array}{c}\text { \% Músculo } \\
\text { Muscle \% }\end{array}$} & \multicolumn{2}{|c|}{$\begin{array}{c}\% \text { Gordura } \\
\text { Fat } \%\end{array}$} & \multicolumn{2}{|c|}{$\begin{array}{l}\% \text { Osso } \\
\text { Bone } \%\end{array}$} \\
\hline & Média & $\mathrm{DP}^{1}$ & Média & $\mathrm{DP}$ & Média & DP \\
\hline & Mean & $S D$ & Mean & $S D$ & Mean & $S D$ \\
\hline Seleção & $59,63^{\mathrm{a}}$ & 4,67 & $21,26^{\mathrm{a}}$ & 5,67 & $19,11^{\mathrm{a}}$ & 2,15 \\
\hline $\begin{array}{l}\text { Selection } \\
\text { Controle } \\
\text { Control }\end{array}$ & $59,50^{\mathrm{a}}$ & 3,80 & $21,98^{\mathrm{a}}$ & 4,68 & $18,50^{\mathrm{b}}$ & 2,06 \\
\hline
\end{tabular}

${ }_{1}^{1}$ Desvio-padrão (Standard deviation).

Médias seguidas de mesma letra, na mesma coluna, não diferem pelo teste $F$ de Snedecor $(P>0,05)$.

Means followed by the same letters, in the same column, do not differ by $F$ test of Snedecor $(P>.05)$.

PERON et al. (1995) também não verificaram diferenças entre grupos genéticos para as proporções de músculo, gordura e ossos. Resultados semelhantes foram relatados por JORGE et al. (1999), avaliando as características de carcaça de quatro raças zebuínas (Nelore, Gir, Guzerá e Tabapuã), nãocastrados, com média de 24 meses de idade, também não encontraram diferenças para nenhuma das características quantitativas e da composição física da carcaça destes animais.

Da mesma forma, outros trabalhos avaliando animais Nelores e seus mestiços com raças européias, nãocastrados, não encontraram influência de grupo genético para as características de composição da carcaça (MOURA et al., 1998; EUCLIDES FILHO et al., 1997).

Freqüentemente, o efeito da nutrição se confunde com o efeito de peso. Portanto, para se fazer comparações válidas entre tratamentos nutricionais, é necessário comparar os grupos de animais ao mesmo peso (corporal ou de carcaça). Isso se constitui na principal dificuldade de se comparar os diferentes resultados da literatura. Conclui-se que, para possibilitar uma compreensão efetiva e abrangente das características de carcaça e composição corporal dos bovinos, deve-se estudar de forma conjunta o padrão de desenvolvimento dos animais, cujos efeitos podem ser marcantes na deposição de osso, músculo e gordura. Os resultados da literatura sobre os efeitos da nutrição ou de regimes alimentares na composição da carcaça e na qualidade da carne são conflitantes.

Os animais provenientes do regime de engorda em confinamento apresentaram (Tabela 7) média de peso de abate $(437,41 \mathrm{~kg})$ significativamente menor que os animais acabados em pastagem $(469,46 \mathrm{~kg})$. O peso é considerado um fator importante na estimativa do rendimento da carcaça, sendo utilizado como parâmetro de comparação entre diferentes carcaças, apesar de não representar uma estimativa adequada de sua composição. Do mesmo modo que entre linhagens, houve diferença significativa $(P<0,05)$ entre os regimes de terminação. Os animais terminados a pasto apresentaram maior peso de abate do que os animais confinados no presente estudo. A média de PCQ dos animais confinados foi de $257,77 \mathrm{~kg}$ e a dos animais terminados a pasto, de $264,83 \mathrm{~kg}$, não se observando diferenças entre os regimes de terminação. LUCHIARI FILHO et al. (1989a) obtiveram PCQ inferiores ao obtido neste trabalho $(249,00 \mathrm{~kg})$, para animais Nelores inteiros em confinamento. GAZZETTA et al. (1995), comparando as características de carcaça de zebuínos da raça Nelore e bubalinos, obtiveram resultados de PCQ $(274,17 \mathrm{~kg})$ superiores ao obtido no presente trabalho.

Quanto ao desempenho dos animais terminados a pasto, os dados da literatura são relativamente escassos, mas igualmente variáveis ao dos animais acabados em confinamento. GAZZETTA et al. (1988), avaliando as carcaças de bovinos da raça Nelore e bubalinos, relatam peso de carcaça quente de $275,00 \mathrm{~kg}$, pouco superior ao obtido neste trabalho. LUCHIARI FILHO et al. (1989b) obtiveram 233,50 kg de PCQ de animais Nelores castrados engordados a pasto, sendo esse peso inferior ao obtido no presente trabalho.

A Tabela 8 exibe as médias e respectivos desviospadrão das características qualitativas da carcaça de acordo com a terminação: AOL, EGS e FC. As diferenças na maciez da carne devidas à nutrição se confundem com os efeitos da idade, já que o animal crescendo lentamente em menor nível nutricional, de 
Tabela 7 - Médias e desvios-padrão do peso de abate (PABATE), peso de carcaça quente (PCQ), rendimento de carcaça quente (RCQ) e peso da gordura renal-pélvica-inguinal (GRPI), conforme o regime de terminação

Table 7 - Means and standard-deviation of slaughter weight (PABATE), hot carcass weight (PCQ), hot dressing percentage (RCQ) and kidney fat weight (GRPI), according to finishing system

\begin{tabular}{|c|c|c|c|c|c|c|c|c|}
\hline \multirow{3}{*}{$\begin{array}{l}\text { Terminação } \\
\text { Finishing }\end{array}$} & \multicolumn{2}{|c|}{ PABATE $(\mathrm{kg})$} & \multicolumn{2}{|c|}{ PCQ (kg) } & \multicolumn{2}{|c|}{$\operatorname{RCQ}(\%)$} & \multicolumn{2}{|c|}{ GRPI(kg) } \\
\hline & Média & $\mathrm{DP}^{1}$ & Média & $\mathrm{DP}$ & Média & DP & Média & DP \\
\hline & Mean & $S D$ & Mean & $S D$ & Mean & $S D$ & Mean & $S D$ \\
\hline $\begin{array}{l}\text { Confinamento } \\
\text { Feedlot }\end{array}$ & $437,41^{b}$ & 35,21 & $257,77^{b}$ & 22,56 & $58,91^{\mathrm{a}}$ & 1,37 & $7,10^{\mathrm{a}}$ & 2,31 \\
\hline $\begin{array}{l}\text { Pastagem } \\
\text { Pasture }\end{array}$ & $469,46^{\mathrm{a}}$ & 44,73 & $264,83^{a}$ & 28,55 & $56,36^{\mathrm{b}}$ & 1,61 & $4,76^{\mathrm{b}}$ & 1,36 \\
\hline
\end{tabular}

${ }^{1}$ Desvio-padrão (Standard deviation).

Médias seguidas de mesma letra, na mesma coluna, não diferem pelo teste $F$ de Snedecor $(P>0,05)$.

Means followed by the same letters, in the same column, do not differ by test $F$ of Snedecor $(P>.05)$.

acordo com as curvas de crescimento alométrico, atinge o ponto de abate em idade mais avançada.

Os animais de pasto apresentaram maior $\left(67,13 \mathrm{~cm}^{2}\right)$ AOL que os de confinamento $\left(63,14 \mathrm{~cm}^{2}\right)$, possivelmente também, em função do maior peso de abate dos animais de pasto. PERON et al. (1995), trabalhando com animais Nelore e $1 / 2$ Nelore-Chianina, $1 / 2$ Holandês-Nelore e 1/2 Gir-Holandês e 3/4 HolandêsGir, obtiveram maiores valores para a AOL e EGS para os animais que apresentaram os maiores tamanhos. Os animais criados a pasto praticamente não apresentaram cobertura de gordura $(0,89 \mathrm{~mm})$, o que certamente penalizaria esses animais numa classificação de novilho precoce. No entanto, os animais de confinamento também apresentaram uma cobertura de gordura deficiente $(1,89 \mathrm{~mm})$, inferior ao mínimo requerido para uma adequada conservação da carcaça em câmara de armazenamento.

Essas informações ratificam a dificuldade de imprimir acabamento adequado para animais nãocastrados em relação a animais castrados.

Isto torna necessário fornecer suplementos energéticos a esses bovinos visando melhorar a deposição de gordura subcutânea. Resultados semelhantes aos obtidos no presente estudo foram relatados por LUCHIARI FILHO et al. (1985, 1989a), para animais confinados.

A quantidade de gordura interna associada aos rins e às cavidades pélvica e torácica também influencia no rendimento da carcaça, embora este parâmetro dependa muito do método de processamento das mesmas (JONES et al., 1978). No Brasil, os matadouros removem esses depósitos de gordura, prática que geralmente não ocorre em muitos outros países
Os resultados do presente estudo contrariam parcialmente as conclusões de MÜLLER e PRIMO (1985), os quais relataram superioridade na qualidade da carcaça de animais Hereford mantidos em melhores níveis nutricionais. Provavelmente, ocorreu no presente estudo, confundimento entre o efeito de peso do animal e o efeito de sistema de terminação.

As características referentes à composição física (\% MUSC, \% GORD e \% OSS) da seção HH dos animais, de acordo com a terminação, podem ser observadas na Tabela 9. Nela pode-se verificar que as características de composição física da carcaça não apresentaram diferenças significativas $(\mathrm{P}>0,05)$ entre os regimes de terminação. Embora não se detectassem diferença estatística, os animais terminados a pasto apresentaram $\%$ MUSC de $60,92 \%$ ligeiramente superiorà obtida pelos animais de confinamento (58,23\%). Pode-se atribuir esse resultado, parcialmente, ao maior PABATE apresentado pelos animais de pasto.

Apesar do melhor nível nutricional, os animais de confinamento não apresentaram maior \% GORD $(23,54 \%)$ do que os animais terminados a pasto $(19,46 \%)$. Esses dados confirmam a possibilidade de se produzir um novilho precoce Nelore com carne predominantemente magra, pois ambos os valores obtidos no presente estudo são inferiores aos observados para a proporção de gordura de bovinos pertencentes a grupos genéticos taurinos (SHACKELFORD et al., 1995).

Outra explicação biológica possível para os resultados do peso da GRPI, da EGS e da \% GORD na carcaça, que expressam a utilização de energia da dieta, pode ser o fato relatado por LANA et al. (1992), de que animais da raça Nelore, com peso vivo acima de $300,00 \mathrm{~kg}$, tendem a apresentar mai- 
Tabela 8 - Médias e desvios-padrão da área do olho de lombo (AOL), espessura de gordura subcutânea (EGS) e força de cisalhamento (FC), conforme o regime de terminação

Table 8 - Means and standard deviation of loin eye area (AOL), fat thickness (EGS) and shear force (FC), according to finishing system

\begin{tabular}{|c|c|c|c|c|c|c|}
\hline \multirow{3}{*}{$\begin{array}{l}\text { Terminação } \\
\text { Finishing }\end{array}$} & \multicolumn{2}{|c|}{$\operatorname{AOL}\left(\mathrm{cm}^{2}\right)$} & \multicolumn{2}{|c|}{ EGS(mm) } & \multicolumn{2}{|c|}{$\mathrm{FC}(\mathrm{kg})$} \\
\hline & Média & $\mathrm{DP}^{1}$ & Média & $\mathrm{DP}$ & Média & DP \\
\hline & Mean & $S D$ & Mean & $S D$ & Mean & $S D$ \\
\hline $\begin{array}{l}\text { Confinamento } \\
\text { Feedlot }\end{array}$ & $63,14^{b}$ & 9,02 & $1,89^{\mathrm{a}}$ & 1,68 & $4,28^{b}$ & 0,83 \\
\hline $\begin{array}{l}\text { Pastagem } \\
\text { Pasture }\end{array}$ & $67,13^{\mathrm{a}}$ & 7,87 & $0,89^{\mathrm{b}}$ & 1,14 & $5,12^{\mathrm{a}}$ & 1,06 \\
\hline
\end{tabular}

1 Desvio-padrão (Standard deviation).

Médias seguidas de mesma letra, na mesma coluna, não diferem entre si pelo teste $F$ de Snedecor $(P>0,05)$.

Means followed by the same letters, in the same column, do not differ by test $F$ of Snedecor $(P>.05)$.

Tabela 9 - Médias e desvios-padrão da porcentagem de músculo, gordura e osso do corte da seção $\mathrm{HH}$, conforme o regime de terminação

Table 9 - Means and standard deviation of percentage of muscle, fat and bone of $\mathrm{HH}$ section, according to finishing system

\begin{tabular}{|c|c|c|c|c|c|c|}
\hline \multirow[t]{3}{*}{$\begin{array}{l}\text { Terminação } \\
\text { Finishing }\end{array}$} & \multicolumn{2}{|c|}{$\begin{array}{l}\% \text { Músculo } \\
\text { Muscle \% }\end{array}$} & \multicolumn{2}{|c|}{$\begin{array}{c}\% \text { Gordura } \\
\text { Fat } \%\end{array}$} & \multicolumn{2}{|c|}{$\begin{array}{l}\% \text { Osso } \\
\text { Bone \% }\end{array}$} \\
\hline & Média & $\mathrm{DP}^{1}$ & Média & $\overline{\mathrm{DP}}$ & Média & DP \\
\hline & Mean & $S D$ & Mean & $S D$ & Mean & $S D$ \\
\hline $\begin{array}{l}\text { Confinamento } \\
\text { Feedlot }\end{array}$ & $58,23^{a}$ & 2,90 & $23,54^{a}$ & 3,43 & $18,21^{\mathrm{a}}$ & 1,77 \\
\hline $\begin{array}{l}\text { Pastagem } \\
\text { Pasture }\end{array}$ & $60,92^{\mathrm{a}}$ & 5,00 & $19,46^{\mathrm{a}}$ & 2,26 & $19,62^{\mathrm{a}}$ & 5,99 \\
\hline
\end{tabular}

${ }^{1}$ Desvio-padrão (Standard deviation).

Médias seguidas de mesma letra, na mesma coluna, não diferem entre si pelo teste $F$ de Snedecor $(P>0,05)$.

Means followed by the same letters, in the same column, do not differ by test $F$ of Snedecor $(P>.05)$.

ores exigências de energia líquida para ganho de peso do que animais mestiços. Portanto, concluiu-se que as dietas de ambos os sistemas de terminação não forneceram as quantidades de energia para atender os requerimentos de produção dos animais.

O efeito do nível nutricional sobre a composição física da carcaça também foi estudado por MÜLLER e PRIMO (1985) em novilhos Hereford submetidos a diferentes regimes alimentares. Esses autores concluíram que os novilhos que receberam melhor regime alimentar apresentaram carcaças de melhor qualidade, evidenciada pelo maior desenvolvimento muscular, boa deposição de gordura subcutânea e menor proporção de ossos.

\section{Conclusões}

Touros de diferencial positivo (Linhagem Seleção), quando comparados com touros de diferencial de seleção nulo (Linhagem Controle) na mesma característica, avaliados pelas suas progênies, obtiveram melhor resultado para peso de abate, superando aqueles em mais de $20 \mathrm{~kg}$.

Não foi registrado efeito de linhagem para nenhuma outra característica da carcaça dos bovinos.

O regime de terminação afetou todas as características analisadas, exceto o peso de carcaça quente, que foi similar para ambos os regimes de terminação.

O grau de acabamento das carcaças dos animais foi muito pequeno, ratificando as dificuldades de se terminar animais não-castrados. Caso a opção seja manter os animais não-castrados, o pecuarista deve administrar uma dieta com teor energético mais elevado se desejar melhorar o grau de acabamento de seus animais.

O moderno novilho Nelore pode produzir uma carcaça com adequada proporção de músculo e gordura, apta a fornecer um tipo de carne magra, que atenda aos anseios do mercado consumidor.

Para possibilitar uma compreensão efetiva e ampla das características de carcaça e composição corpo- 
ral dos bovinos, seria desejável estudar de forma conjunta o padrão de desenvolvimento dos animais, cujos efeitos podem ser marcantes na deposição de osso, músculo e gordura.

\section{Referências Bibliográficas}

AARON, D.K., FRAHM, R.R., BUCHANAN, D.S. 1986. Direct and correlated responses to selection for increased weaning or yearling weight in Angus cattle. II. Evaluation of response. J. Anim. Sci., 62(1):66-76.

ALLEONI, G. F. Avaliação da gravidade específica da carcaça, da composição química e física, dos cortes da costela para estimar a composição corporal de novilhos Nelore na fase de acabamento. Jaboticabal, 1995. 58p. Tese (Doutorado em Zootecnia) - Faculdade de Ciências Agrárias e Veterinárias/ Universidade Estadual Paulista, 1995.

CHAMPAGNE, J.R., CARPENTER, J.W., HENTGER JR, J.F. et al. 1969. Feedlot performance and carcass characteristics of young bulls and steers castrated at four ages. J. Anim. Sci., 29(6):887-90.

EUCLIDES FILHO, K., EUCLIDES, V.B.P., FIGUEIREDO, G.R. et al. 1997. Avaliação de animais Nelore e de seus mestiços com Charolês, Fleckvieh e Chianina, em três dietas. 2. Características de carcaça. R. Bras. Zootec., 26(1):73-79.

FELÍCIO, P.E., NORMAN, G.A. 1978. Curso internacional sobre tecnologia da carne bovina. Instituto de Tecnologia de Alimentos. Campinas. Paginação descontínua.

FIELD, R.A. 1971. Effect of castration on meat quality and quantity. J. Anim. Sci., 26(6):1217-25.

GALVÃO, J.G., FONTES, C.A.A., PIRES, C.C. et al. 1991. Características e composição física da carcaça de bovinos nãocastrados, abatidos em três estágios de maturidade (estudo II) de três grupos raciais. R. Soc. Bras. Zootec., 20(5):502-12.

GAZZETTA, M.C.R.R., NOGUEIRA, J.R., CAMPOS, B.E.S. et al. Avaliação das carcaças de bovinos Nelore e bubalinos Mediterrâneo e Jafarabadi, terminados em pastagem de capim colonião (Panicum maximum Jacq.) In: REUNIÃO ANUAL DA SOCIEDADE BRASILEIRA DE ZOOTECNIA, 25, 1988, Viçosa. Anais... Viçosa: SBZ, 1988. p. 290.

GAZZETTA, M.C.R.R., SCHOKEN ITURRINO, R. P., CAMPOS, B.E.S. et al. 1995. Avaliação corporal de búfalos (Bubalus bubalis) e bovinos Nelore (Bos indicus), terminados em confinamento. Bol. Ind. Anim., 52(1):77-86.

HANKINS, O.G., HOWE, P.E. Estimation of the composition of beef carcasses and cuts. Washington, USDA, 1946. (Tech. Bulletin - USDA, 926)

JACOBS, J.A., HURST, C.E., MILLER, J.C. et al. 1977. Bulls versus steers. I. Carcass composition wholesale yields and retail values. J. Anim. Sci., 45(4):695-98.

JONES, S.D.M., PRICE, M.A., BERG, R.T. 1978. Review of carcass density, its measurement and relationship with bovine carcass fatness. J. Anim. Sci., 46(5):1151-58.

JORGE, A.M., FONTES, C.A.A., PAULINO, M.F. et al. 1999. Desempenho produtivo de animais de quatro raças zebuínas, abatidas em três estádios de maturidade. 2. Características da carcaça. Rev. bras. zootec., 28(2):381-87.

KASTNER, C.L., HENDRICKS, R.L. 1969. Providing uniform meat scores for mechanical shear force measurement. J. Food Sci., 34(6):603.
KOCH, R.M., DIKEMAN, M.E., CROUSE, J.D. 1982. Characterization of biological types of cattle (Cycle III). III. Carcass composition, quality and palatability. J. Anim. Sci., 54(1):35-45.

LANA, R.P., FONTES, C.A.A., PERON, A.J. et al. 1992. Composição corporal e do ganho de peso e exigências de energia, proteína e macroelementos minerais ( $\mathrm{Ca}, \mathrm{P}, \mathrm{Mg}, \mathrm{Na}$ e K), de novilhos de cinco grupos raciais. 2. Exigências de energia e proteína. R. Soc. Bras. Zootec., 21(3):528-35.

LEME, P.R. Estimativa da composição química corporal de novilhos Nelore através do espaço de Deutério. Jaboticabal, UNESP, 1993. 78p. Tese (Doutorado em Zootecnia) -Faculdade de Ciências Agrárias e Veterinárias/Universidade Estadual Paulista, 1993.

LORENZONI, W.R., CAMPOS, J., GARCIA, J.A. et al. 1986. Ganho de peso, eficiência alimentar e qualidade da carcaça de novilhos búfalos, nelores, holandeses e mestiços holandêszebu. R. Soc. Bras. Zootec., 15(6):486-97.

LUCHIARI FILHO, A., BOIN, C., ALLEONI, G.F. et al. 1985. Efeito do tipo de animal no rendimento da porção comestível da carcaça. I. Machos da raça Nelore vs. cruzados zebu x europeu terminados em confinamento. Bol. Ind. Anim., 42(1):31-39.

LUCHIARI FILHO, A., BOIN, C., CESAR, S.M. et al. 1981. Estudo comparativo das características de carcaças de tourinhos Nelore, meio-sangue Marchigiana-Nelore e meio sangue Chianina-Nelore. Bol. Ind. Anim., 38(1):9-17.

LUCHIARI FILHO, A., LEME, P.R., RAZOOK, A.G. et al. 1989a. Características de carcaça e rendimento da porção comestível de machos Nelore comparados a cruzados $\left(\mathrm{F}_{1}\right)$ obtidos do acasalamento de touros das raças Canchim, Santa Gertrudis, Caracu, Holandês e Suíço com fêmeas Nelore I. Animais inteiros terminados em confinamento. Bol. Ind. Anim., 46(1):17-25.

LUCHIARI FILHO, A., LEME, P.R., RAZOOK, A.G. et al. 1989b.Características de carcaça e rendimento da porção comestível de machos Nelore comparados a cruzados $\left(\mathrm{F}_{1}\right)$ obtidos do acasalamento de touros das raças Canchim, Santa Gertrudis, Caracu, Holandês e Suíço com fêmeas Nelore. I. Animais castrados terminados a pasto. Bol. Ind. Anim., 46(1): 27-35.

MACNEIL, M.D., URICK, J.J. NEWMAN, S. et al. 1992. Selection for post weaning growth in inbreeds Hereford cattle: the Fort Keogh Montana line 1 example. J. Anim. Sci., 70(3):723-33.

MOURA, A.C., LUCHIARI FILHO, A., JUNQUEIRA, F.J. 1998. Avaliação de carcaças de bovinos jovens $1 / 2$ beefalo + $1 / 2$ Nelore, $1 / 2$ Canchim $+1 / 2$ Nelore e Nelore tipo comercial. R. Bras. Zootec., 27(4):797-800.

MOLETTA, J.L., RESTLE, J. 1996a. Influência do grupo genético sobre as características qualitativas da carne de novilhos. R. Soc. Bras. Zootec., 25(5):866-875.

MOLETTA, J.L., RESTLE, J. 1996b. Características de carcaça de novilhos de diferentes grupos genéticos terminados em confinamento. R. Soc. Bras. Zootec., 25(5):876-888.

MÜLLER, L. 1980. Normas para avaliação de carcaças e concursos de carcaças de novilhos. Santa Maria: UFSM. 31p.

MÜLLER, L., PRIMO, A.T. 1986. Influência do regime alimentar no crescimento e terminação de bovinos e na qualidade da carcaça. Pesq. Agropec. Bras., 21(4):445-52. 
NATIONAL RESEARCH COUNCIL - NRC. 1984. Nutrient requirements of beef cattle. 6.Rev.Ed. Washington, D.C.: National Academy Press. 90p.

NORMAN, G.A. 1982. Effect of breed and nutrition on the productive traits of beef cattle in southeast Brazil: part 3 Meat quality. Meat Sci., 9(1):76-96.

PERON, A.J., FONTES, C.A.A., LANA, R.P. et al. 1995. Medidas quantitativas e proporções de músculos, tecido adiposo e ossos da carcaça de novilhos de cinco grupos genéticos, submetidos à alimentação restrita e "ad libitum". R. Soc. Bras. Zootec., 24(1):126-37.

RAZOOK, A.G., FIGUEIREDO, L.A., BONILHA NETO, L.M. 1994. Diferenças observadas em progênies de touros Nelore, testados em prova de ganho de peso e com diferenciais de seleção nulo ou positivo para peso pós-desmama, em um rebanho P.O. Bol. Ind. Anim., 51(1):87-98.

RESTLE, J., GRASSI, C., FEIJÓ, G.L.D. 1994. Características de carcaça de bovinos de corte inteiros ou castrados em diferentes idades. Pesq. Agropec. Bras., 29(10): 1603-07.

SAINZ, R.D. Qualidade das carcaças e da carne bovina. CONGRESSO BRASILEIRO DAS RAÇAS ZEBUÍNAS, 2, 1996, Uberaba. Anais...Uberaba: ABCZ, 1996, Paginação descontínua.
SAS Institute SAS/STAT software: changes and enhancements through release 6.12. Cary, Statistical Analysis System Institute, 1997. $1167 \mathrm{p}$.

SHACKELFORD, S.D., WHEELER, T.L., KOOHMARAIE, M. et al. 1995. Relationship between shear force and trained sensory panel tenderness ratings of 10 major muscles from $B o s$ indicus and Bos Taurus cattle. J. Anim. Sci., 73(11):3333-40.

WHEELER, T.L., SAVELL, J.W., CROSS, H.R. et al. 1990. Mechanisms associated with the variation in tenderness of meat from Brahman and Hereford cattle. J. Anim. Sci., 68(12):4206-20. 